\title{
ASPECTOS DO REALISMO E DA VIOLÊNCIA NA LITERATURA
}

\author{
Andre Rezende Benatti
}

RESUMO: Este artigo tem como objetivo uma apreciação de alguns aspectos que envolvem o realismo e a violência na Literatura, para tal tomamos como objetos de estudo que nos auxiliarão na compreensão dos conceitos contos da escritora hispano-paraguaia Josefina Plá, a saber "La pierna de Severina", "La Vitrola", "Sisé" e "Siesta". Para tal, nos valeremos dos estudos sobre real e o realismo de Roman Jakobson, Roland Barthes e Tânia Pellegrini, entre outros, assim como dos estudos da violência de Hannah Arendt, Xavier Crittiez e Karl Erik Schollhammer.

PALAVRAS-CHAVE: Realismo; Violência; Representação; Literatura.

\section{Sobre o início}

Para Massaud Moisés (2004, p. 378) em Dicionário de termos literários, o realismo, de maneira geral, "designa toda tendência estética centrada no "real", entendido como a soma dos objetos e seres que compõe o mundo concreto e social.”. Desta forma, percebemos o realismo enquanto possível em escritas literárias desde os primórdios da Literatura. Ora, se há algum objetivo em um texto literário, talvez seja que este represente o real, de acordo com a perspectiva de cada época. Poderíamos imaginar, por exemplo, a seguinte pergunta a um escritor "romântico": "Sua obra representa a realidade?", talvez a resposta a esta pergunta seria "Sim, meus textos representam o real.". Claro a uma pergunta da ordem da imaginação há de se ter também uma resposta imaginativa, contudo, como saber se sob toda e qualquer perspectiva teórica e estética, seja ela romântica, barroca ou moderna, os escritores não representavam, cada um a seu modo, uma realidade.

\footnotetext{
${ }^{*}$ Doutor em Letras Neolatinas: estudos literários neolatinos (literaturas hispânicas) pela Universidade Federal do Rio de Janeiro (UFRJ). Professor adjunto da Universidade Estadual de Mato Grosso do Sul (Uems), onde atua como Professor permanente do Programa de Pós-graduação em Letras. Docente do quadro permanente do Programa de Pós-graduação em Estudos de Linguagens da Universidade Federal de Mato Grosso do Sul (UFMS).
} 
De acordo com Maria Teresa Gramuglio em Império Realista (2002), representar o real se constrói como o objetivo central da obra de arte literária em prosa. Podemos perceber o realismo enquanto uma atitude que atravessa diversos séculos da Literatura, uma atitude que acompanha a humanidade. Bakhtin, em suas análises de Cultura Popular na Idade Média e no Renascimento (2010), encontra nestes períodos, por exemplo, forma de representação da realidade. Contudo o autor não concebe o realismo na literatura como mera temática que perpassa uma obra. O realismo é estético. Assim, pretendemos explorar as nuances que tendem, na literatura, à representação do real e da violência na América Latina, esta última enquanto algo pertencente à própria formação deste lugar.

Conforme afirma Candido, em Literatura e sociedade (2014), procurar, no texto literário, o meio social, ou seja, esta realidade imediata, não se justifica por si só, pois, tal texto não é uma cópia da realidade real e por isto motivo não serve para definir esse meio. O meio social só se torna relevante quando é uma parte interna que integre e qualifique a própria narrativa, sendo possível revisitar as forças colocadas em choque na conformação social.

A literatura é uma instituição social que utiliza, como meio de expressão específico, a linguagem - que é uma criação social. Processos literários tão tradicionais como o simbolismo e o metro - são, por natureza, sociais. Constituem convenções e normas que só podiam ter surgido em sociedade. Acresce que a literatura "representa" a "vida": e a vida é, em larga medida, uma realidade social, não obstante o mundo da Natureza e o mundo interior ou subjectivo do indivíduo terem sido, também, objecto de "imitação literária". (WELLEK; WARREN, s/d, p. 113)

Toda a realidade social que é representada na obra de arte literária existe antes e independente à obra. Assim refletimos sobre uma literatura que exprime uma realidade social. Voltando à Gramuglio (2002), representar a realidade, é pensar a representação estética desta sociedade. Aventamos a Literatura Latino-americana como um espaço no qual tal sociedade é permeada por uma violência visceral desde sua criação. Há uma violência sistemática ocorrendo na literatura produzida na América Latina ao longo de sua história e 
que perdura até a contemporaneidade. Apesar de ponderarmos que a sociedade representada na obra não é e jamais será a mesma sociedade que existe fora dela, pois, se há um objetivo da literatura, este não é representar a realidade empírica, o que há na obra literária é a construção um novo mundo, capaz de refletir parcial e opacamente a sociedade externa, porém seguindo seus próprios padrões e estruturas narrativas. E é desta sociedade, que desempenha algum papel na estrutura textual, que nos ateremos ao analisar as narrativas latino-americanas, como esta literatura internaliza e elege como estética narrativa a violência pertencente à sociedade externa ao objeto literário

[...] o que interessa é averiguar que fatores atuam na organização interna, de maneira a construir uma estrutura peculiar. Tomando o fator social, procuraríamos determinar se ele fornece apenas matéria (ambiente, costumes, traços grupais, idéias), que serve de veículo para conduzir a corrente criadora (nos termos de Lukács, se apenas possibilita a realização do valor estético); ou se, além disso, é elemento que atua na constituição do que há de essencial na obra enquanto obra de arte (nos termos de Lukács, se é determinante do valor estético). (CANDIDO, 2014, p. 6)

Partindo do ponto em que a Literatura possui um contato extremamente estreito com a realidade externa a ela, contato este que oscila entre depender e se rebelar, Ronaldo Lima Lins (1990), afirma que na compreensão da natureza literária, se aceita o princípio de que a arte se revela tendo como uma de suas funções a mudança de alguma coisa em seu apreciador.

\section{Sobre o realismo}

A literatura, e assim a percebemos desde Aristóteles, é mimética, o termo grego conceitua a faculdade humana de "reproduzir", de "imitar". Para Aristóteles a mimesis representa o que há de fundamental em toda arte, o que difere do conceito platônico de mimesis, para quem tudo o que é criado pelo homem, independentemente de ser arte ou não é "imitação". Aderindo à concepção aristotélica de mimesis, pensamos a arte literária como "imitação" da realidade. Para Aristóteles 
[...] não é ofício do poeta narrar o que aconteceu; é, sim, o de representar o que poderia acontecer, quer dizer: o que é possível segundo a verossimilhança e a necessidade. Com efeito, não diferem o historiador e o poeta por escreverem verso ou prosa [...] diferem, sim, em que diz um as coisas que sucederam, e outro as que poderiam suceder. Por isso a poesia é algo de mais filosófico e mais sério do que a história, pois refere aquela principalmente o universal, e esta o particular. (ARISTÓTELES, 1987. p. 209)

Assim, podemos conjecturar que o real se constrói no texto literário como uma possibilidade. Algo que, por conta de sua coerência construtiva, torna-se possível de acontecer naquele mundo criado pelo escritor.

Roman Jakobson, em "Do realismo na arte" (2013), nos alerta para três possíveis apreciações acerca do conceito de realismo; "chama realista a obra que o autor em questão projetou como verossímil.", "chamam realista a obra que quem julga percebe como verossímil.", e, por fim, chamam realistas "a soma dos traços característicos de uma escol artística do século XIX.” (2013, p, 110-111). Podemos perceber, a partir de Jakobson, que o conceito de realismo é bastante variável, assim, tratar de tal temática torna-se algo escorregadio. Afinal, como podemos afirmar que tal obra é ou não realista?

Slavoj Zizek, em Violência (2014, p. 24), afirma que a diferença entre o real e a realidade, em uma visão lacaniana, é que “a 'realidade’ é a realidade dos indivíduos efetivos implicados em interações e nos processos produtivos, enquanto o Real é a inexorável e ‘abstrata' lógica espectral do capital que determina o que se passa na realidade social'. Percebemos, com isso, que, em se tratando de Literatura, a realidade perpassa a vida das personagens, dentro da diegése, fazendo com que o texto ganhe ares de "real", este real abstrato do qual fala Zizek (2014) e que faz parte do funcionamento de uma sociedade. São atitudes destas personagens que determinarão em menor ou maior grau a realidade social dentro da obra. 
Jakobson (2013) ressalta que, para um teórico da arte o termo Realismo corresponde a uma corrente artística que busca reproduzir fielmente a realidade, prezando pela verossimilhança dentro da obra, ou seja, que segue a lógica do texto. Logo, são declaradas realistas as obras que nos parecem verossímeis.

No conto "La vitrola", conhecemos Delpilar, a personagem principal do conto de Josefina Plá, que vive em um mundo à parte, construído dentro do mundo real, desde pequena quando ouviu o som do fonógrafo do vizinho. Delpilar aprende a desligar-se do mundo e a viver em transe.

[...] D. Pedro, el vecino del Doctor, compro el fonógrafo. A partir de aquel instante, Delpilar entró en trance, y ya no se pudo sacar de ella más nada. Sonaba el fonógrafo - que sonar, sonaba a menudo, a la hora más imposible y a todo pulmón - y Delpilar desaparecía. (PLÁ, 1996, p. 175)

A realidade no texto da autora nos remete, em certos momentos, a fatos da realidade história que se apresentam, devido à própria construção textual, de maneira a convencer o leitor daquela forma de conta-los.

Cuando estalló la guerra del Chaco, Delpilar, con treinta y siete años a cuestas, hacía rato que se había emancipado de la tutela encomendera de Doña Fausta. Se ganaba la vida por su cuenta, ya actuando como cocinera en tal cual santo ara, ya vendiendo verduras o lavando. No que tuviera para ninguna de esas cosas mucha gracia. Los pastelitos salíanle argeles, aplastados como alpargatas viejas; la ropa que lavaba tenía un sospechoso color de batata cocida; sus verduras eran invariablemente mustias y los huevos que ofrecía, pequeños y sucios como sobrante de clueca. Seguía siendo flaca y renegrida, canillas de pájaro; en su cutis reseco aparecía ya la pauta de las próximas incontables arrugas. (PLÁ, 1996, p. 176)

A verossimilhança das narrativas da autora e a capacidade de convencimento são dois dos "trunfos", digamos assim, da apresentação e representação da realidade social em seus contos, aliados à construção sólida das personagens, sem as quais a representação da realidade seria impossível. A Guerra do Chacho, conflito armado entre Paraguai e Bolívia, 
serviu, neste caso, de pano de fundo para as impressões sobre a personagem que são criadas no leitor, tornando-a mais "real". O termo "realista" aponta para o sentido, grosso modo, de fidelidade como evidenciado por Jakobson (2013).

$\mathrm{Na}$ literatura realista, a verossimilhança com a realidade é destacada em situações que acontecem de fato ou que aconteceriam, a identificação do público com o que é representado é precisa. Contudo, a verossimilhança não é a mais absoluta de todas as características que compõe o realismo, como grosso modo se pensa, quando pensamos no conceito do realismo e/ou da realidade, também devemos pensar no afastamento da imitação, como afirma Barthes:

O realismo não pode ser [...] a cópia das coisas, mas o conhecimento da linguagem; a obra mais 'realista' não será a que 'pinta' a realidade, mas a que, servindo-se do mundo como conteúdo (este mesmo conteúdo é, aliás, alheio à sua estrutura, isto é, ao seu ser), explora o mais profundamente a realidade irreal da linguagem. (BARTHES, 2004, p. 164)

Quando Barthes cita Flaubert, que descreve "um velho piano que suportava, sob um barômetro, um monte piramidal de caixas" (apudBARTHES, 2004, p. 181), ele conduz seu leitor a determinado ambiente pelos elementos que cita, indicando, por exemplo, a condição financeira, de posses da família. Contudo, ao trazer o barômetro, objeto que indica as prováveis mudanças de tempo, e o amontoado de caixas que povoam o imaginário do leitor, o autor constróis uma cena que, por seus objetos, não acrescenta nada ao enredo propriamente dito, mas que se tornam relevantes para a constituição do espaço em seus mínimos detalhes, fazem parte da ambientação, da própria verossimilhança. $\mathrm{Na}$ realidade empírica, embora não tenhamos, na maioria das vezes, pianos e barômetros, em nossas casas, temos diversos outros objetos que compõe o espaço e/ou ambientação de nossas vidas, mas que, com ou sem os mesmos, não haveria qualquer diferença em nossa história. Estas pequenas coisas que aparecem nos textos, mas que necessariamente não influencia no enredo são "o efeito do real" projetado por Barthes. Como, por exemplo, no início do conto "Siesta", de Josefina Plá, que narra a trágica história de violências e sofrimentos de 
Maria, em que o narrador nos apresenta uma magnífica ambientação para nos contar, posteriormente, uma história de violência e incesto.

El sol cae como estaño derretido, salpicando destellos en los guijaroos azulados. Las hojas de las palmeras y cocoteros en los patios están quietas como de metal, y tienen el mismo bruñido resplandor. Dentro de la pieza bien cerrada, la penumbra vibra silenciosa ante el asedio diluvial de la luz. El sol proscrito se filtra aquí y allá por sutiles rendija de puertas y ventanas, transflorando delgados esquemas amarillos. Es siesta, una siesta de enero; y Ciriaco no puede dormir. Le molestan el calor y la luz oceánica, invisible pero asediadora; le enerva, en la pared frontea de la cama, el móvil cono de sombra que traza y destraza el ir y venir de la chiquilina atrafagada limpiando el corredor. María debería estar descansando; pero Doña Ceferina ha salido, no volverá hasta las tres; y la vieja no permite que en su ausencia la chiquilina esté ociosa. María pasa y vuelve a pasar por delante de la puerta, y el leve roce del repasador sobre las baldosas sería adormecedor, sin los chasquidos del balde en que moja el trapo de tanto en tanto. Ese chasquido breve, leve como de ramita quebrada, es lo que le impide conciliar el sueño y le irrita.[...] (PLÁ, 1996, p. 187)

Desviando a atenção do leitor para elementos pouco ou nada relevante ao enredo do texto, da história em si, como o narrador de Plá faz, no trecho acima, temos o que Barthes opera como efeito do real, cada partícula do texto é responsável pela composição da realidade a ser apresentada a quem o lê. A partir deste ponto inicial do conto, é que o a personagem de Ciriaco, tentará estuprar a filha. Contudo, Barthes (2004) critica o fazer mimético tradicional do realismo e a reprodução do real vivido ao dizer que o real não é representável, mas demonstrável.

Ao apresentar a concepção de Realismo Refratado, em Realismo: modos de usar (2012), Tânia Pellegrini dialoga com Barthes (2004) quando afirma que ao realismo, não cabe ser a cópia da realidade, mas o conhecimento da linguagem, que se serve do mundo como seu conteúdo.

O realismo a que me refiro parece operar esteticamente, ao longo da história, uma refração da realidade e não uma 'cópia', uma 'imitação' 
ou mesmo 'interpretação', no sentido aristotélico, o que permite entender sua continuidade como corolário da persistência do mesmo 'mundo hostil' que lhe deu origem.(PELLEGRINI, 2012, p. 12)

Pellegrini (2012) afirma que o realismo continua vivo na literatura e presente nas formas narrativas contemporâneas. Além do efeito do real e a fabricação da realidade, ao lidar com o termo realismo nos deparamos com outra nuance presente em seus conceitos, a violência. Um questionamento destacado por Renato Cordeiro Gomes no ensaio "Por um realismo cruel e brutal", presente no livro Novos Realismos (2012) nos leva a refletir:

Estariam os meios massivos pondo em imagens atos de crueldade até o limite do suportável? Poderíamos colocar no mesmo plano todo tipo de imagem agressiva, sem levar em conta a intenção, o contexto e o sentido da ação mostrada nas telas? (GOMES, 2012, p. 73)

A utilização da violência como artifício literário tem se tornado cada vez mais complexa devido a banalização que vem sofrendo, o tema violência passa a ser apenas mais um aspecto da vida contemporânea, logo, trabalhar com esse conceito requer muita habilidade e cuidado, para que a banalização não supere o impacto que a mesma deve ter sob o leitor. Nesse ponto, Josefina Plá se realça ao trabalhar com a violência de modo que o conceito não sobressai sobre seu enredo, o foco não é a violência, mas sua obra é construída a partir dela.

É essa ação, calcada na violência, que se faz como componente da estética das narrativas literárias de Josefina Plá, como se pode verificar na parte final do conto "La Pierna de Severina”, no qual Plá conta a história de Severina e seu desejo em se tornar parte da sociedade:

Severina volvió a su trabajo tras la ventana. Y ya no expresó más su deseo de ser Hijade María. Cuando alguien extrañado le preguntaba si no pensaba ya en eso, Severina bajaba la vista y contestaba con vOz monótona:

— Eso pasó todo. Una renga como yo no sirve luego para Hija de María.

Pero en la siguiente fiesta de la Virgen apareció cambiado el mantel del altar mayor. Un mantel con la-bores de Nanduti como no se 
había visto hasta entonces. Era el obsequio de Severina a Nuestra Señora. (PLÁ, 1996, p. 173)

Com clareza também se pode perceber dentro desse pequeno trecho do conto como, por consequência da violência, Severina silencia-se, configurando assim uma nova forma de violência, dessa vez contra si própria, sabotando suas convicções de outrora. Portanto, o silêncio dentro desse, assim como de outros contos, se constrói como uma nova violência. Nos contos de La Pierna de Severina, a violência está presente em todos e das mais variadas formas.

\section{Sobre a violência}

De acordo com Xavier Crettiez (2011), pensar a respeito da violência, seja ela qual for, política, social, psicológica, etc., está presente no núcleo de toda vida humana. Pensamos a violência o tempo todo, mesmo que inconscientemente. Ao reformarmos nossas casas e elevarmos as alturas dos muros, instalarmos cercas elétricas ou câmeras filmadoras, ao recomendarmos "Cuidado!" ou "Se cuide!" a quem sai de nossas casas, por exemplo, estamos pensando, de alguma forma, a violência.

Presente em nossa vida cotidiana, a violência é difícil de ser definida, aliás como qualquer outro conceito oriundo das ciências humanas. É difícil pensar o humano. Assim, também é difícil pensar a violência se pensarmos que o humano está entre as poucas espécies do reino animal que escraviza o outro, e talvez seja a única que violenta o outro gratuitamente.

A violência não é somente uma ação de coerção; é também uma pulsão que pode ter como finalidade apenas sua expressão, satisfazendo assim certa cólera, ódio, um sentimento negativo, que buscam a se concretizar. O objetivo não é constranger, mas exatamente aviltar, destruir ou se construir pela passagem ao ato. (CRETTIEZ, 2011, p. 11)

Assim, se pensarmos na História que aprendemos nas escolas durante toda nossa vida, temos a percepção de que tudo o que nos foi transmitido, todos os assuntos, temas e 
períodos históricos sobre os quais aprendemos necessariamente estão marcados por algum tipo de violência. Guerras, abusos de poder, intolerâncias religiosas e raciais; violências físicas, morais, sociais e psicológicas; toda a evolução da raça humana é regida por conflitos. Por isso, a vida humana é marcada por uma série de traumas, e por conta da proximidade que há entre a realidade empírica e o universo literário, fica difícil pensar a literatura separadamente da apreciação a respeito da violência, principalmente na literatura do século XX.

Nos contos de Plá, a violência está presente nas mais variadas formas. No conto "Siesta", por exemplo, Maria, a personagem principal, é exposta a violências de todos os tipos em sua própria casa. Morando com o pai, que não a reconhece como filha, nem ao menos olha para a garota, e com a avó, que explora a menina, obrigando-a a realizar os trabalhos domésticos, a vida de Maria sofre pequenas, mas significativas, violências diárias, seu crescimento como ser humano é "podado", como se seus sentimentos e suas habilidades fossem galhos de uma árvore, devendo encontrar formas de amparo, que não as familiares, para resistir e não sucumbir à dor e ao sofrimento. $\mathrm{O}$ ato mais marcante da violência no conto está no ataque sofrido por Maria por seu pai.

Ciriaco sonríe. Una sonrisa torcida, que le hace horrible de ver. Toma a la pequeña del brazo violentamente. Mate y pava caen al suelo. La boca de la chica se crispa de terror. Cree que va a golpearla. - Papá...

- Yo no soy su papá... me oye, grandísima idiota!... La puta de tu madre se lo cree, no más... Pero yo no soy tu padre... y me la van a pagar.

María siente que un calambre doloroso y nauseante le sube desde el estómago. Los miembros se le entorpecen. Ciriaco se ha levantado, la aprieta entre sus brazos esmirriados, que no podrían sostener una pelea con otro macho, pero que bastan para ahogar a una niña de once años. Con una mano le tapa la boca, con la otra busca bajo sus falditas desteñidas y la pellizca obsceno. La chiquilina gime afónica de terror; una reacción puramente instintiva, primaria, la lleva de pronto a prender ciegamente sus dientes en la mano que la amordaza. Y muerde con una desesperación de animalito en cepo. (PLÁ, 1996, p. 194)

A pequena Maria escapa de seu pai por um ato puramente instintivo, mas cega pelo 
mesmo ato acaba por ser atropelada e morta em frente à sua casa, em sua última desventura desesperada. A violência a salvou, matando-a, marcando a tragicidade presente na vida de Maria, no ato final que a salva do estupro, porém a leva à morte.

De acordo com Ronaldo Lima Lins,

[...] a violência define o meu semelhante como um monstro e lhe dá, em situações limites, a possibilidade de subir os degraus da natureza humana e dignificá-la através de ações extraordinária. É, assim, inimiga e aliada, combatida e cultivada, um motivo de vergonha e um motivo de orgulho. (1990, p. 22)

Para Hannah Arendt (2011), a violência se faz por conta da ausência da autoridade e controle, logo, por conta disso, o homem se perde no que possui como mais instintivo dentro de si. Ainda de acordo com a filósofa, desde o começo da existência humana a violência se faz presente. O homem sempre perdeu e perderá a autoridade e o controle. Exacerbando os pensamentos de Arendt, poderíamos pensar que a própria evolução do homem, se aliarmos às conquistas histórias que aprendemos durante nossa vida escolar, se deu por meio das violências cometidas pelo homem. De acordo com Arendt (2011, p. 79), a

[...] agressividade, definida como um impulso instintivo, diz-se que ela representa o mesmo papel funcional, no âmbito da natureza, que os instintos sexuais e os de nutrição do processo vital do indivíduo e da espécie. Mas diferentemente desses instintos, que, por um lado, são ativados por necessidades corporais prementes, e, por outro, por estímulos externos, os instintos agressivos no reino animal parecem ser independentes de tal provocação; ao contrário, a falta de provocação conduz aparentemente à frustração do instinto, ao 'recalque' da agressividade, que de acordo com alguns psicólogos, causa o bloqueio da 'energia' cuja conseqüente explosão será extremamente perigosa. [...] Segundo essa interpretação, a violência sem provocação é 'natural'; se ela perdeu sua rationale, basicamente, a sua função na autopreservação, tornou-se 'irracional', e essa é supostamente a razão pela qual os homens podem ser mais 'bestiais' do que outros animais.

São homens que, confusos em relação ao que os cerca, buscam em sua própria natureza uma explicação para sua agressividade, no entanto, fazendo isso, acabam, por 
conta de sua racionalidade, tornando-se irracionais, mais selvagens que outros animais. Portanto, não é surpresa que a literatura pense sobre a violência e sobre a agressividade humana das mais diversas maneiras, expondo cruamente a violência humana, como nos contos "La Pierna de Severina" e "Sisé", ambos violentos:

Em "La Pierna de Severina” lemos a seguinte cena:

Aturdidamente despierta los sintió, más que los vio, con terror, acercarse en la sombra. Uno se inclinó sobre ella, la palpó con manos obscenas y duras.

— Ndé lo mita. Eyú coápe. Miren pue lo que hay acá.

- Peteí cuñá. Oh. Añamemby. Regalo del cielo.

Un coro de piiipus estremecedores subió en el aire de la alta noche. El que se había acercado primero hizo el descubrimiento.

— Es renga nipo raé.

La contestación no se demoró.

- Renga o retymá carë, lo mismo sirve.

Le corearon risas que a Severina le sonaron como risas de Satanás. Manoteando en espontánea defensa, Severina pudo notar que uno de esos hombres era manco: un duro muñón caliente le rozaba la sien. Sintió arcadas. Después ya no pudo más darse cuenta exacta de nada. Todo tan brutal, y tan subitáneo. Aquel rebullir espeso de machos hediendo a sudor agrio y mugre antigua. El airecillo premonitor de la madrugada la encontró sola, devuelta al centro del silencio, como si todo hubiese sido una pesadilla. Un vago lampo de conciencia arrastró el cuerpo maltrecho a lo largo de la calle hasta encontrar aquel portal abierto a desusadas horas. (PLÁ, 1996, 171-172)

O assombro da violência sexual se faz presente dando ao leitor grande repulsa a tudo o que acontece a Severina, tanto o ato, quando as atitudes da sociedade que fez com que a personagem chegasse ao ponto da vulnerabilidade que a levou a ser violentada. A personagem vive em meio a uma sociedade criada por Plá para ser uma representação do descaso com o essencial para a manutenção da vida física, mas, de maneira antitética, fazendo com que se preserve o básico da vida do espírito. O caso de Severina vem à tona como consequência do mundo criado pela contista e que é uma crítica às sociedades ocidentais marcadas pelo patriarcalismo, pela violência e pela presença da Igreja Católica.

Já no conto "Sisé" é narrada a história de Sisenanda, ou simplesmente Sisé, uma menina que perde a mãe ao nascer e que é encontrada por empregados de uma fazenda no 
interior do Paraguai. Nessa ambientação campesina, Sisé é criada como se fosse um animal do lugar, bebendo no mesmo vasilhame que os porcos: “[...] Le dio leche, con la misma mamadera del chanchito [...] (PLÁ, 1996, p. 196), e comendo sobras de ossos: “[...]La criatura sentada en el suelo de la cocina, chupaba un hueso que la cocinera le pasaba de su plato[...] (PLÁ, 1996 p. 196). Toda a violência a que a personagem é exposta no desde o início da narrativa vai aumentando cada vez mais até chegar ao ato mais extremo de todo o texto:

Fue al terminar esa misma primavera un día lluvioso, pero no de noche sino de siesta, cuando el patrón llamó a Sisé a su pieza, cerró la puerta, la tomó en vilo del brazo, la echó en la cama y desplomó sobre ella sus ochenta kilos de musculatura recia y de hueso pesado. Sisé creyó que el patrón la iba a matar: desorbitó los ojos, quiso sin duda gritar; pero el hombre le apretó la boca con su mano enorme como la paleta de blandear los bifes - india de mierda, cállate - y la mantuvo muda a la fuerza durante mucho rato. Cuando la echó del cuarto, quedándose él boca arriba con el aire del que ha comido demasiado, Sisé se limpió con el borde del vestido. No se le movía un músculo del rostro, pero un agua lustrosa le corría mejillas abajo. La cocinera que vio antes que nadie el vestido manchado, rezongó ásperamente algo, pero no le pegó esta vez. Le pasó por las mejillas su delantal de dudosa limpieza, le dio otro vestido y quemó aquél en el fogón de la cocina.

Se convirtió en una costumbre del patrón.[...] (PLÁ, 1996. p. 199200)

Esta é a vida de Sisé até que ela, atingindo certa idade, começa a tomar formas mais femininas, momento em que outra torrente de violência ingressa em sua vida, passando a ser estuprada primeiramente pelo dono da fazenda, depois por seus filhos. A violência segue até que Sisé engravida e é encontrada morta junto a seu filho em uma manhã de Natal, o que se mostra irônico: a morte no dia da celebração da vida do "salvador", no cristianismo.

O que se tem de violento não somente na literatura de Josefina Plá, mas também no panorama geral da literatura produzida especialmente a partir do século XX, é como um espelho da vida social do homem, ao mesmo tempo vítima e algoz a serviço do capitalismo e das intolerâncias, marcas de um século $(\mathrm{XX})$ que viveu boa parte de seu transcurso 
imerso entre a Primeira Guerra Mundial, a quebra financeira do final da década de 1920, a Segunda Guerra Mundial, seguida da Guerra Fria e da formação de regimes ditatoriais tanto de direita quanto de esquerda, conflitos que também marcam o século XX por demasiado do mesmo modo na Hispano-América, como as questões relativas à revolução e o comunismo cubanos, a ditadura chilena e argentina, as constantes crises políticas e econômicas do Paraguai, todas elas gerando climas totalmente violentos. Portanto, não há como desvencilhar a violência, que é um fator constitutivo do ser humano, da produção literária. Contudo, imagens de violência são, no século XXI, distribuídas ao bel-prazer no cotidiano humano, sem qualquer filtro ou mediação.

Segundo Renato Cordeiro Gomes (2012, p. 73), no ensaio "Por um realismo cruel e brutal",

[...] estamos condenados a dar voltas ao redor de uma violência que se pretende cada vez mais natural e que já não se apresenta como experiência. "Não se está condenado a reciclar a violência quando são se logra sair dela?" Ou: "como reciclar a violência se o excesso e a irrisão fracassam, incapazes de interromper o fluxo das imagens e da violência?”.

Uma pergunta nos inquieta: por que a violência foi tão presente no cotidiano do século XX? A resposta talvez esteja na forma com que o homem foi criado a partir de suas ideologias, sua sede por poder e o não conformismo com a falta dele, o que, conforme afirma Hannah Arendt (2011), leva ao impulso violento. Talvez seja por sua pulsão cruel, por ser a única forma deste sujeito sentir algo. Pedro Lyra (1980, p. 34) assevera que "[...] o que ocorre com a violência é semelhante ao que ocorre com a inflação: se todos saíssem perdendo, ela já teria acabado" (itálicos do autor).

Há no ser humano a busca constante pelo domínio sobre outros homens e sobre as coisas e quando não há controle sobre tal ânsia de poder de dominação, há a geração da violência. Por outro lado, alguém sempre está ganhando poder com o descontrole e a violência de outros. Logo, representar literariamente a violência funciona como um espelho questionador, como já o fizera na literatura inglesa Virginia Woolf, assim como autores 
consagrados da literatura brasileira, dentre eles, Clarice Lispector, que cria sua violentada e silenciada Macabéa. Josefina Plá revela com clareza, por vezes em demasia, a violência e os subprodutos dessa ação: dor, sofrimento, estupro e morte.

A literatura de Josefina Plá, no tocante especialmente aos contos de La Pierna de Severina, assim como em diversas outras narrativas, até mesmo nas narrativas infantis, deixa de ser uma literatura dedicada especialmente ao que se convencionou chamar de "prazer", produzida nos séculos XIX e anteriores, passando a ser o que Roland Barthes (2002) chama de "texto de fruição", que coloca em estado de incômodo, de angustia aquele que a lê, perturbas todas suas bases referenciais, o faz entrar em constante crise. E podemos completar: assim como em relação a tudo o que o cerca social, ideológica e psicologicamente.

Em contraponto ao que afirma Tânia Pellegrini (2018), em Realismo e realidade na Literatura, quando a crítica se opõe, em certa medida, à presença constante da violência nos textos da literatura brasileira contemporânea. A violência nos textos de Josefina Plá, não é mero pretexto para desenvolvimento das personagens, tampouco é a protagonista das histórias. Contudo, se faz presente nas criações de cada um dos textos da autora. Nos arriscamos dizer, as estruturas sociais representadas por Plá em suas narrativas são constituídas de violências, mas, também são formadas por pessoas, ou seja, há violência está, de alguma forma, entranhada no funcionamento social e, se voltarmos ao pensamento de Candido (2014), exerce determinada função no construto do texto narrativo, ela é parte importante na constituição das próprias microestruturas.

Karl Erik Schollhammer, ao pensar a violência e o realismo na literatura brasileira afirma que:

Quando estabelecemos uma relação entre a violência e as manifestações culturais e artísticas, é para sugerir que a representação da violência manifesta uma tentativa viva da cultura [...] de interpretar a realidade contemporânea e de se apropriar dela, artisticamente, de maneira mais "real", com o intuito de intervir nos processos culturais. $(2013$, p. 43$)$

Ou seja, a violência precisa ser pensada e representada nos diversos contextos e meios, pois ela é parte integrante e atuante do contexto social e cultural. Não há como nos 
desvencilharmos dela. Seja simbólica, física ou psíquica, seja justificada, injustificada ou instintiva, a violência se faz presente em nosso cotidiano.

\section{Sobre o final}

A violência nunca compreende a comparação de duas experiências, no entanto o significante sobrenada em toda ação social. Embora pareça, a nós, um absurdo, somente no meio social totalitário o ser humano não conhece a noção de violência, pois ele só reconhece a posição de quem ocupa o poder. E aqui tomamos as concepções de Hannah Arendt, em Sobre a Violência (2011), nas quais a filósofa distingue violência de poder, que na ausência deste é que a violência se faz, e como se pode ser percebido por meio da história, os regimes totalitários são regidos pelo poder extremo de seus governantes, logo os dominados, submersos no regime, não conseguem ter a noção da violência. Por conseguinte, o que nós, cidadãos de "mundos" teoricamente divididos e conscientes, chamamos de violências, os habitantes dos mundos totalitários conferem nomes que marcam a estranheza, a ruptura das regras de suas sociedades. Portanto, como nos afirma Leenhart (1990), quem não partilha das normas do poder e o manifesta, torna-se herético, terrorista, parasita, etc.

Conforme afirma Eduardo Galeano em Las venas abiertas de América Latina, desde a invasão europeia no século XVI - e aqui se entende invasão como ação de invadir, como incursão feita contra um ou mais povos, por uma força militar - a América Latina vem sendo violentada.

No século XX, de acordo com Hannah Arendt em Sobre a violência, surge à categoria "genocídio", até então desconhecida e não tipificada juridicamente. Em contraponto à afirmação arendtiana, o já referido Galeano afirma que a invasão do continente americano no século XVI resultou no extermínio de milhões de indígenas.

Segundo Darcy Ribeiro, citado por Galeano,

Los indios de las Américas sumaban no menos que setenta millones, y quizá más, cuando los conquistadores extranjeros aparecieron en 
el horizonte; un siglo y medio después, se habían reducido, en total, a solo tres millones y medio. (2011, p. 58-59)

Deste modo, não se pode, no contexto atual, deixar de pensar a invasão da América Latina e o extermínio indígena perpetrados pelos europeus, ainda que não tipificados, como genocídio. O conceito de violência, bem como outros conceitos relativos às ciências humanas, possui matizes que por vezes se confundem e confundem os estudiosos: eles podem ser concernentes a um choque entre manifestantes e policiais em uma reunião acadêmica; à morte de seis milhões de judeus nos Lager nazistas; ou ao extermínio de mais de sessenta milhões de indígenas durante a conquista de toda a América. Ou ainda à escravização negra que, durante séculos, provocou a morte de milhões de africanos e seus descendentes na América como um todo.

Em um continente invadido, violentado e usurpado, formado por processos de mestiçagens os mais diversos, os tons da violência por vezes estão dissimulados, no mais das vezes, pela linguagem. E se pensarmos, ainda mais longe, donde vem nossa linguagem, nossa referência prima, voltamos à pequena região do Lácio na qual se originou a latinidade. Latinidade essa que por séculos passou pelos mais variados tipos de conflitos e violências, e que se misturou e se reinventou, e se renovou, e se refez das mais diversas formas, pelos mais diversos contatos, seja com povos "bárbaros", seja com povos "indígenas", até chegar ao novo mundo e ser novamente reinventada.

A “imitação da realidade”, lembrando Aristóteles, empírica que ocorre na literatura é constituída pelas microestruturas textuais, que constroem a obra pautada nas formas da vida real, porém com algo a mais, como a imaginação e a fantasia humanas. São as microestruturas que (con)formarão o que há no texto: seus sentidos, as impressões, são estas mesmas microestruturas que representação ou demonstrarão esta realidade violenta que se faz presente em nossas sociedades. 


\section{ASPECTOS DEL REALISMO Y LA VIOLENCIA EN LA LITERATURA}

RESUMEN: Este artículo tiene como objetivo apreciar algunos aspectos que involucran realismo y violencia en la literatura, para esto lo tomamos como objetos de estudio que nos ayudarán a comprender los conceptos de la escritora hispano-paraguaya Josefina Plá, a saber, "La pierna de Severina “,” La Vitrola “," Sisé “y” Siesta “. Para ello, utilizaremos los estudios sobre realismo y realismo de Roman Jakobson, Roland Barthes y Tânia Pellegrini, entre otros, así como los estudios de violencia de Hannah Arendt, Xavier Crittiez y Karl Erik Schollhammer.

PALABRAS CLAVE: Realismo; Violencia; Representación; Literatura

\section{REFERÊNCIAS}

ARENDT, Hannah. Sobre a violência. Trad. André Duarte. Rio de Janeiro: Civilização Brasileira, 2011.

ARISTÓTELES. Poética. Tradução de: SOUZA, Eudoro de. São Paulo: Nova Cultural, 1987. p. 209.

BAKHTIN, Mikhail Mikhailovich. Cultura popular na idade média e no renascimento: o contexto de François Rabelais - $7^{\mathrm{a}}$ edição. Trad. Yara Frateschi Vieira. São Paulo: Hucitec, 2010 .

BARTHES, Roland. O efeito de real. In: O rumor da lingua. Trad. Mário Laranjeira. São Paulo: Cultrix, 2004.

CANDIDO, Antonio. Literatura e sociedade. Rio de Janeiro: Ouro sobre azul, 2014.

CRITTIEZ, Xavier. As formas da violência. Tradução de Lara Christina de Malimpensa e Mariana Paolozzi Sérvulo da Cunha. São Paulo: Edições Loyola, 2011.

GALEANO, Eduardo. Las venas abiertas de América Latina. Barcelona: Siglo Veintiuno Editores, 2011.

GRAMUGLIO, Maria Teresa. El imperio realista. Tomo 6. Noé Jitrik (Dir.) Historia crítica de la literatura argentina. Buenos Aires: Emecé, 2002.

GOMES, Renato Cordeiro. Por um realismo brutal e cruel. In: MARGATO, Izabel; . (Org.). Novos Realismos. Belo Horizonte: Editora UFMG, 2012.

JAKOBSON, Roman. Do realismo na arte. In: TODOROV, Tzvetan. Teoria da literatura: textos dos formalistas russos. Trad. Roberto Leal Ferreira. São Paulo: Editora UNESP, 2013.

LEENHARDT, Jacques. O que se pode dizer da violência? In.: LINS, Ronaldo Lima. Violência e literatura. Rio de Janeiro: Tempo Brasileiro, 1990. 
LINS, Ronaldo Lima. Violência e literatura. Rio de Janeiro: Tempo Brasileiro, 1990.

PELLEGRINI, Tânia. Realismo: modos de usar. In: Estudos de Literatura Brasileira Contemporânea, n.39, p. 11-17, 5 jun. 2012.

PLÁ, Josefina. Cuentos completos. Miguel Ángel Fernández. Asunción (org.), Asunción: El Lector, 1996.

SCHOLLHAMMER, Karl Erik. A cena do crime: violência e realismo no Brasil contemporâneo. Rio de Janeiro: Civilização Brasileira, 2013.

WELLEK, René; WARREN, Austin. Teoria da literatura. 4. ed. Lisboa: Europa-América, s.d.

Recebido em: 22/01/2020.

Aprovado em: 29/05/2020. 